\title{
Effect of Online Reviews on Consumer Purchase Behavior
}

\author{
Zan Mo, Yan-Fei Li, Peng Fan \\ School of Management, Guangdong University of Technology, Guangzhou, China \\ Email: 649319529@qq.com
}

Received 27 May 2015; accepted 26 June 2015; published 29 June 2015

Copyright (C) 2015 by authors and Scientific Research Publishing Inc.

This work is licensed under the Creative Commons Attribution International License (CC BY). http://creativecommons.org/licenses/by/4.0/

c) $\underset{\mathrm{EY}}{\mathrm{P}}$ Open Access

\begin{abstract}
In order to understand the effect of online reviews on consumer purchase behavior, more than 400 Taobao shops' online reviews are collected. Based on S-O-R model (Stimulus-Organism-Response Model), this paper studies the influence on consumer purchase behavior according to online reviews of experience goods from a new perspective of consumer learning. Using SPSS 19.0 software for data analysis and assumptions, statistical results show that the positive reviews, describing rating, picture reviews, appended reviews and cumulative reviews have an effect on consumer purchase behavior. The moderate reviews, negative reviews, logistics rating and service rating are not significant in the results. Finally, this paper puts forward suggestions and summary.
\end{abstract}

\section{Keywords}

Online Reviews, Consumer Learning, Experience Goods, Purchase Behavior

\section{Introduction}

The development of e-commerce websites led consumers to become accustomed to online shopping. According to iResearch latest data show that in Figure 1 [1], in 2014, the 3rd quarter of Chinese online shopping market transaction size was 691.41 billion RMB, B2C market accounted for $44.2 \%$ and Tmall accounted for nearly $60 \%$ in B2C market. C2C market can meet online consumers' differences and individual needs, which will continue to maintain a steady growth in the future. The 35th survey report released by CNNIC showed that [2], up to December 2014, the scale of Chinese Internet users reached 649 million, of which mobile phone users reached 557 million. Mobile shopping is becoming more and more popular.

Before consumers make a purchase in an e-commerce website, they are accustomed to use online reviews information as a basis to judge whether they purchase. After consumers buy it, they will post their own comments of the commodity in the e-commerce sites. In recent years, the study of online reviews discuss usefulness and 


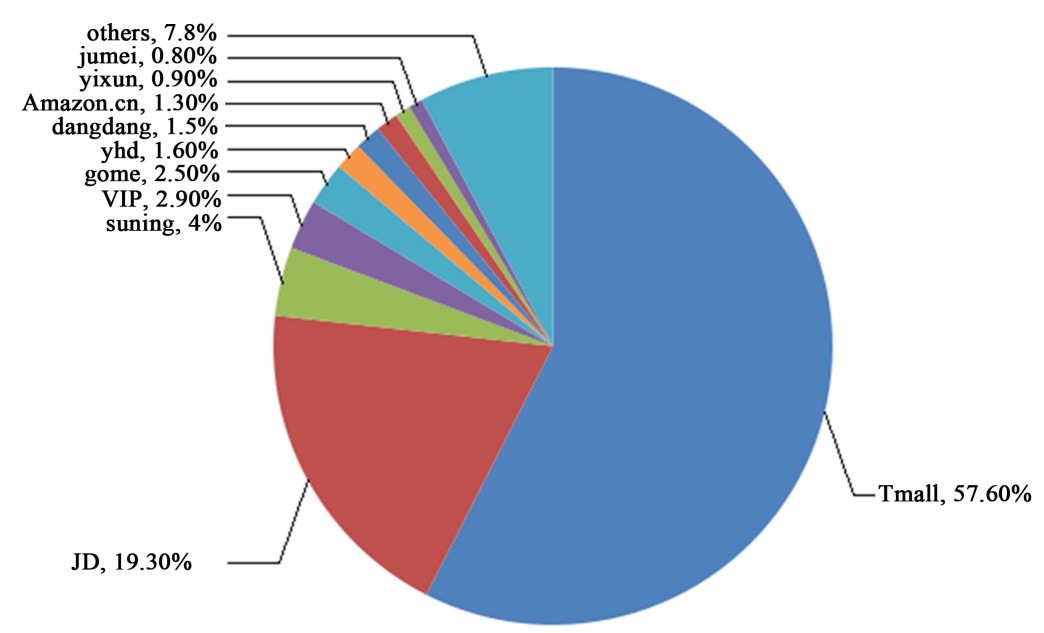

Figure 1. Chinese B2C shopping sites transaction size in the third quarter of 2014.

credibility mainly. This paper collects the reviews information of experience goods in Taobao, to study how online reviews affect purchase behavior during the purchasing process.

\section{Theory Foundation}

There are many kinds definitions of online reviews. Different scholars have different views. Park and Lee [3] believe that online reviews are positive and negative reviews of the products have been sold on the online shopping mall. Mudambi and Schuff [4] point out that online reviews are evaluation information of products and service pasted on third-party sites and retailers, which created by the consumers. This paper believes that online reviews are evaluation information about the different aspects of consumer products. With this information, consumers can infer the quality of goods according to the reviews and experience, to reduce personal time and the risk of purchase.

In general, quantitative study of how online reviews affect consumer purchasing behavior can be transformed into a study of how online reviews affect merchandise sales. By the research on online reviews and movie box office revenues, some scholars found using sales to measure consumer buying behavior was feasible in the quantitative measure [5]. Therefore, this paper studies how online reviews affect consumer purchase behavior via monthly commodity transaction records.

Online reviews information on Taobao is anonymous. Because of asymmetry, consumers can not get all of the information before buying. They have to collect online reviews before buying in order to raise awareness. Online reviews provide consumers with real shopping experience, and a reference to understand the products. Some scholars believe that the driving force of consumers to search online reviews are asymmetric information, lack of available information, the cognitive perception authority and perceptual economic. So searching online reviews behavior of consumers before buying is an important step. Meanwhile, online reviews can improve consumer perception of shopping sites and products, attract consumers caring potentially, and increase consumer loyalty and sense of community to the site, which allows consumers to make better shopping decisions [6].

As consumers' guide information, anonymous transmission of online reviews make more consumers are willing to provide their own real-life experience, even if it is a negative one. But the sellers will take action to force consumers to rewrite the negative reviews information, making some of the information cannot be trusted. Furthermore, some Taobao sellers take harassment and retaliation to the customers who give negative reviews. So the customers are afraid to give real comments. Besides, brushing reputation behavior makes consumers cannot distinguish which transaction is fake, increasing judging difficulty according to the comments.

Consumer learning refers to the process that consumers acquire knowledge, experience, skills, and improve their buying behavior constantly during the purchase. Consumers' attitudes are affected by the quantity and ratings of online reviews. When consumers want to buy thing, they are hinted by the positive or negative comments, they will like or dislike the goods. When high-quality reviews emerging, consumer impulse will continue to get strengthened. When low-quality reviews emerging, consumer impulse is reduced. After their purchase, the 
quality of goods is recognized by consumers. When there is demand to buy again, they will make a repeat purchase. Online reviews of credibility and usefulness adoption process can be understood as a kind of consumer learning behavior. So observing consumer buying process from the point of consumer learning becomes very necessary.

Watson, the founder of behavioral psychology, proposed "stimulus-response" model. On the basis of it, Mehrabian proposed consumer behavior model, Stimulus-Organism- Response Model (SOR model) [7]. This model indicates that the scenario can stimulate consumers' psychology, and then affect consumer behavior. This paper studies the impact of online reviews on consumer purchasing behavior, shown in Figure 2. The stimulus comes from the rating and comment of online reviews. Review rating refers to positive review, moderate review, and negative review of the goods. This paper analyzes how the quantity of review rating affects consumer behavior. Review content refers to two aspects: the quantity of reviews and shop reputation. The shop reputation includes description rating, logistics rating and service rating. The quantity of reviews refers to the quantity of pictures reviews, the quantity of additional reviews and the quantity of cumulative reviews.

\section{Hypotheses}

From an economic point, Nelson divided goods into search goods and experience goods. Search goods means the goods that consumers will be able to get accurate information before buying according to the information, such as mobile phones, cameras, printers and so on. Experience goods refers to the goods that consumer cannot obtain accurate information from product information before the purchase, such as cosmetics, food, and so on. The results of foreign research show that experience good is more dependent on online reviews than search good, and consumer tend to use online reviews while buying experience goods [8] [9]. Therefore, this paper studies online reviews of experience goods.

Currently, the reviews systems of different e-commerce sites aren't exactly the same. But they are all involved in logistics rating, services rating, description rating and comment review. On Taobao product pages, websites offer consumers the chance to post reviews with content in the form of numerical star ratings (ranging from 1 to 5 stars). We can find a variety of information related to online reviews, such as pictures reviews, additional reviews, positive reviews, moderate reviews, negative reviews, cumulative reviews and others. Which one will have an impact on sales? This paper will discuss the factors one by one.

\subsection{Review Rating}

Review rating of goods is the initial attitude of consumer, which is evaluated by the consumer on goods. The reviews systems of B2C and C2C are slightly different. C2C review system involves positive reviews, moderate reviews and negative reviews, while B2C does not have this option. In this paper, we study how the quantity of these star rating on C2C website (Taobao) affect consumer purchase behavior. Consumers update the attitude of goods according to the star ratings, which is one of the consumers learning process. Some study show that, the quantity of positive reviews plays a significant role in the consumer decision making, the quantity of moderate reviews have no impact, the negative reviews have negative impact on consumers buying behavior.

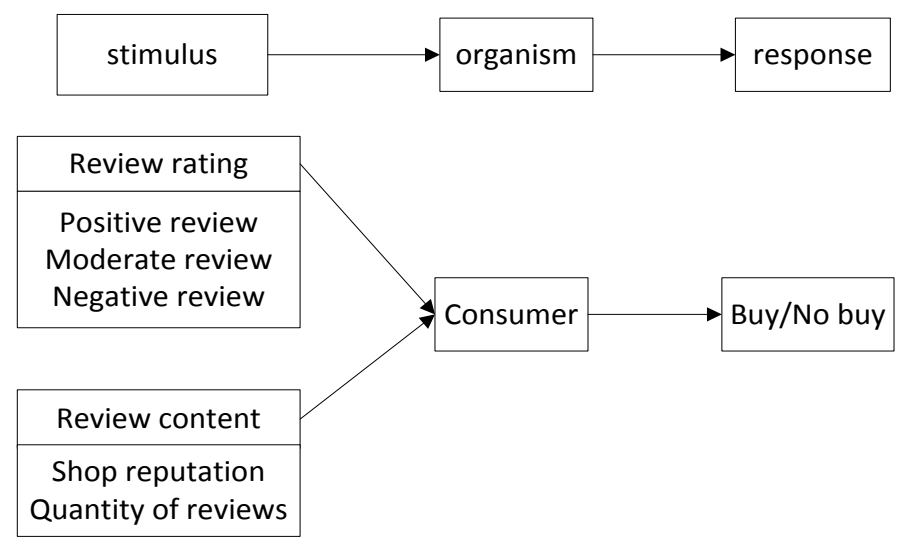

Figure 2. SOR model of consumer purchase. 
Therefore, the following hypotheses are provided:

H1a: Positive reviews have a positive effect on consumer buying behavior.

H1b: Moderate reviews have no effect on consumer buying behavior.

H1c: Negative reviews have a negative effect on consumer buying behavior.

\subsection{Review Content}

1) Shop Reputation

Shop reputation refers to the content evaluation and star ratings given by the consumers after the purchase. Content evaluation may involve the comment of quality, price, service attitude, logistics and so on. Consumers can also show pictures of the goods below the content form. In addition to the content evaluation, customer needs to give star ratings about logistics, services and description. Star rating rang from one to five stars. A very low rating (one star) indicates bad quality, bad service and slow logistics. A very high rating (five stars) reflects good quality, good service and fast logistics. Five stars are the best and one star is the worse. Shop reputation is one of the intangible assets and one of the attracting factors. Study has shown that the star rating can increase consumer confidence.

Therefore, the following hypotheses are provided:

H2a: Description star rating positively affects consumer buying behavior.

H2b: Service star rating positively affects consumer buying behavior.

H2c: Logistics star rating positively affects consumer buying behavior.

2) Quantity of Reviews

Pictures are formed in the consumers' first review or additional reviews, which is one part of reviews. The reviews containing pictures reflect the real quality of the goods, such as color problem, specifications inconsistent problem, or the high quality, good experience. The picture reviews reduce consumer's risk during buying experience goods. In the consumer learning process, picture reviews indicates the real buying behavior.

Consumer can complete the comment within 180 days. After that, the seller will give evaluation to the consumer, too. But consumers have a second chance to append reviews, and sellers have another chance to explain too. Additional reviews refer to the second reviews. It can be text or pictures, but does not affect the seller's star rating. Additional reviews reflect the consumer experience better. Thus additional reviews reflect a real situation after purchase. The quality problem of some commodities will not appear in a short time. Via additional reviews, consumer can understand the quality and durability of goods. Some scholars use complex network approach to study additional reviews of lotion in Taobao, and found that the time presents long-tailed distribution with a specific regularity.

Cumulative reviews are reviews posted within a month. The reviews may involve color, quality, specification, logistics, customer service and other factors. The reviews can be done a long tirade, also can be a short word evaluation, such as good or bad. Cumulative review is an important channel for consumer to understand goods information before buying. The high richness information can help consumers understand product information deeply. Some study show that the influence of positive reviews replaces the influence of cumulative reviews. But another study found that the quantity of online reviews affect the willingness of consumers to buy on the network.

In summary, the following hypotheses are provided:

H3a: The additional reviews have a positive impact on consumer buying behavior.

H3b: The picture reviews have a positive impact on consumer buying behavior.

H3c: The cumulative reviews have a positive impact on consumer buying behavior.

\section{Data Collection, Analysis and Results}

Based on the following reasons, this paper selects cleanser as the research object. First, cleanser is an experience product, consumer buy it for personal use or give others as gifts, avoiding comparisons and other emotional factors to make a purchase. Second, this product is a daily use product. Consumers have different experience with each other, excluding the impact of consumers' personal feelings about the brand effect.

Taobao website offers 30 days of transaction records and reviews records. So this paper collects 30 days sales on Taobao for the study. We select online data from November 15, 2014 to December 15, 2014 as data sample, including 440 shops' sales information of Shiseido cleanser on Taobao. The total number of reviews is 218954. Removing invalid evaluation, data sample involves 434 shops' information. 
The descriptive statistics for all variables are included in Table 1. The minimum value of positive reviews, moderate reviews, negative reviews is 0 . Different shops have different sales. Some shops sold this product little and no one gives reviews. So the minimum value is 0 . The mean of moderate reviews and negative reviews is less than 3. Because consumers don't often give moderate review or negative review, so the mean is small. The minimum value of description rating, services rating and logistics rating are 4.5 , the maximum is 5 , the mean is about 4.8 (out of 5), showing the three rating of 434 shops have little difference. The minimum value of pictures reviews, additional reviews and cumulative reviews are 0 . The mean of picture reviews and additional reviews is about 10. It costs consumers more time and effort to post pictures and additional reviews. If the product does not appear any problems, consumers do not give additional reviews and pictures especially.

The results of the regression analysis are included in Table 3. From the regression result of model 1 , the analysis of the model indicates a good fit, with a highly significant likelihood ratio $(p=0.000)$, and R-square value of 0.888 , shown in Table 2. In H1, we hypothesized that positive reviews have a positive impact, moderate reviews have no impact, and negative reviews have negative impact. We find strong support for H1a. Positive review is a highly significant $(p<0.000)$ predictor of consumer buying behavior. The results also provide support for H1b, which hypothesizes moderate reviews have no impact on consumer buying behavior. The results don't provide support for H1c. So the hypothesis that negative reviews have negative impact on consumer buying behavior is not significant in this study.

Table 1. Descriptive statistics for full sample.

\begin{tabular}{cccccc}
\hline Variable & $\mathrm{N}$ & Minimum & Maximum & Mean & Standard Error \\
\hline Positive reviews & 407 & 0 & 25084 & 221.04 & 1344.989 \\
Moderate reviews & 407 & 0 & 371 & 2.67 & 19.424 \\
Negative reviews & 407 & 0 & 241 & 1.5 & 12.68 \\
Description star rating & 434 & 4.4 & 5 & 4.814 & 0.0695 \\
Services star rating & 434 & 4.4 & 5 & 4.832 & 0.0689 \\
Logistics star rating & 434 & 4.5 & 5 & 4.826 & 0.0748 \\
Picture reviews & 434 & 0 & 929 & 11.89 & 68.739 \\
Cumulative reviews & 434 & 0 & 26476 & 381.77 & 1936.304 \\
Additional reviews & 434 & 0 & 919 & 10.44 & 51.202 \\
Monthly sales & 434 & 7 & 11189 & 161.99 & 669.49 \\
\hline
\end{tabular}

Table 2. Model summary.

\begin{tabular}{ccccccc}
\hline Model & $\mathrm{R}$ & $\mathrm{R}$ Square & Adjusted R Square & Std. Error of the Estimate & Sig. F & Durbin-Watson \\
\hline 1 & 0.888 & 0.789 & 0.789 & 314.424 & 0 & 1.988 \\
2 & 0.874 & 0.765 & 0.762 & 326.296 & 0.029 & 1.943 \\
\hline
\end{tabular}

Table 3. Regression output for full sample.

\begin{tabular}{|c|c|c|c|c|c|c|}
\hline & \multirow{2}{*}{ Model } & \multicolumn{2}{|c|}{ Unstandardized Coefficients } & \multirow[t]{2}{*}{ Standardized Coefficients } & \multirow{2}{*}{ t-value } & \multirow{2}{*}{ Sig. } \\
\hline & & B & Standard Error & & & \\
\hline \multirow{2}{*}{1} & (Constant) & 56.193 & 15.795 & & 3.558 & 0 \\
\hline & Positive reviews & 0.452 & 0.012 & 0.888 & 38.941 & 0 \\
\hline \multirow{5}{*}{2} & (Constant) & 2431.711 & 1088.115 & & 2.235 & 0.026 \\
\hline & Additional reviews & 10.252 & 0.652 & 0.784 & 15.73 & 0 \\
\hline & Picture reviews & 2.614 & 0.564 & 0.268 & 4.635 & 0 \\
\hline & Cumulative reviews & -0.065 & 0.017 & -0.189 & -3.786 & 0 \\
\hline & Description star rating & -494.982 & 225.956 & -0.051 & -2.191 & 0.029 \\
\hline
\end{tabular}


From the regression results of model 2, the analysis of the model indicates a good fit, with a highly significant likelihood ratio ( $p=0.029$ ), and an R-square value of 0.847 , shown in Table 2 . In H2, we hypothesized that description star rating positively affected consumer buying behavior, service star rating positively affected consumer buying behavior, logistics star rating positively affected consumer buying behavior. We find describing rating negatively affects consumer buying behavior. H2a gets an opposite support. Service star rating and logistics star rating have no effect in this study. $\mathrm{H} 2 \mathrm{~b}$ and $\mathrm{H} 2 \mathrm{c}$ get no support. In model 2, we find strong support for H3a and H3b. The additional reviews and picture reviews are highly significant $(p<0.000)$ predictor of consumer buying behavior. In H3c, picture reviews have an opposite effect. Cumulative reviews negatively affect consumer buying behavior.

\section{Conclusion}

This paper discusses the impact of online reviews on consumer buying behavior. It collects a brand of cleanser on Taobao website as the research object. The results show that the influential factors of online reviews on consumer buying behavior include positive reviews, description rating, picture reviews, additional reviews and cumulative reviews. The four factors, moderate reviews, negative reviews, service star rating and logistics star rating, are not significant in this research. Therefore, the sellers can take the incentives for consumers to make positive reviews and high quality reviews in the sales process. For example, cash, coupons, member points are good incentive to encourage consumers to post additional reviews and show pictures actively. So the sellers must also improve the quality of their goods in order to increase comment information. The conclusion of this paper can help consumers make decisions quickly based on online reviews in a short time. It can also help sellers to grasp the importance of online reviews, correct deficiencies timely and provide a reference for the adjustment of marketing strategy. Besides, this is a cross-sectional study and it fails to investigate the longitudinal effect of online reviews on consumer purchase behavior. Other scholars can study the longitudinal effect in future research.

\section{Fund}

This study is funded by National Natural Science Foundation of China: 71171062.

\section{References}

[1] iResearch (2014) iResearch Quarter Report [EB/OI]. http://report.iresearch.cn/html/20141105/241068.shtml

[2] CNNIC (2015) The 35th Statistical Report on China Internet Network Development [EB/OI]. http://news.xinhuanet.com/politics/2015-02/03/c 127453226.htm

[3] Park, C. and Lee, T.M. (2009) Information Direction, Website Reputation and eWOM Effect: A Moderating Role of Product Type. Journal of Business Research, 62, 61-67. http://dx.doi.org/10.1016/j.jbusres.2007.11.017

[4] Mudambi, S.M. and Schuff, D. (2010) What Makes a Helpful Review? A Study of Customer Reviews on Amazon. com. MIS Quarterly, 34, 185-200.

[5] Duan, W.J., Gu, B. and Whinston, A.B. (2008) The Dynamics of Online Word-of-Mouth and Product Sales-An Empirical Investigation of the Movie Industry. Journal of Retailing, 84, 233-242. http://dx.doi.org/10.1016/j.jretai.2008.04.005

[6] Kumar, N. and Benbasat, I. (2006) Research Note: The Influence of Recommendations and Consumer Reviews on Evaluations of Websites. Information Systems Research, 17, 425-439. http://dx.doi.org/10.1287/isre.1060.0107

[7] Mehrabian, A. and Russell, J.A. (1974) An Approach to Environmental Psychology. The MIT Press, Cambridge.

[8] Senecal, S. and Nantel, J. (2004) The Influence of Online Product Recommendations on Consumers' Online Choices. Journal of Retailing, 80, 159-169. http://dx.doi.org/10.1016/j.jretai.2004.04.001

[9] Bei, L.T., Chen, E.Y. and Widdows, R. (2004) Consumers' Online Information Search Behavior and the Phenomenon of Search vs. Experience Products. Journal of Family and Economic Issues, 25, 449-467. http://dx.doi.org/10.1007/s10834-004-5490-0 